\title{
Effect of Manganese Addition on 94NBT-6BT Lead Free Multilayer Ceramics
}

\author{
Mert Gul ${ }^{1,2, *}$, Mevlüt Gurbuz ${ }^{3}$, Abdi B. Gokceyrek ${ }^{4}$, Aysegül Toktaş ${ }^{4}$, Taner Kavas ${ }^{1}$, Aydın Dogan $^{2,4}$ \\ ${ }^{1}$ Department of Materials Science and Engineering, Afyon Kocatepe University, Turkey \\ ${ }^{2}$ Nanotech High Tech Ceramics Co., Eskisehir, Turkey \\ ${ }^{3}$ Department of Mechanical Engineering, Ondokuz May is University, Turkey \\ ${ }^{4}$ Department of Materials Science and Engineering, Iki Ey lül Technical University, Turkey \\ Received December 6, 2019; Revised January 17, 2020; Accepted February 7, 2020
}

Copyright $\odot 2020$ by authors, all rights reserved. Authors agree that this article remains permanently open access under the terms of the Creative Commons Attribution License 4.0 International License

\begin{abstract}
In this study, lead-free $94 \mathrm{Bi}_{0,5} \mathrm{Na}_{0,5} \mathrm{TiO}_{3}-$ $6 \mathrm{BaTiO}_{3}(94 \mathrm{NBT}-6 \mathrm{BT})$ ceramics were fabricated by solidstate synthesis method at ambient atmosphere. Glassy phase and rounded particles in 94NBT-6BT was observed with increasing $\mathrm{Mn}$ content. The effects of doping manganese on the ferroelectric properties of 94NBT-6BT bulk ceramics were evaluated. From the XRD results of the calcined powders, peaks were slightly changed to higher 2 theta value while increasing manganese ratio. Multivalence additive $\mathrm{Mn}$ ions act as acceptor dopant in 94NBT-6BT structure at ambient atmosphere. Samples were sintered from $1075^{\circ} \mathrm{C}$ to $1175^{\circ} \mathrm{C}$ for 2 hours to obtain highest piezoelectric values. SEM results show that glassy phase and rounded particles in 94NBT-6BT was observed with increasing Mn content so, bulk density was enhanced up to $1125 \mathrm{C}$. From the results, $0.3 \mathrm{wt} \%$ manganese doped 94NBT-6BT samples have highest electromechanical coupling factor about 0.23 , mechanical coupling factor (Qm) 150 and $d_{33} 110 \mathrm{pC} / \mathrm{N}$ respectively. Further work, 94NBT-6BT and Mn-doped 94NBT-6BT multilayer actuators were manufactured by water-based tape casting technique. The active area was $49 \mathrm{~mm}^{2}$ MLA and was fabricated by using Ag-Pd internal electrode without Pd-Bi reaction at the electrode-ceramic interface. Hysterisis loop measurements of manufactured lead free actuators were done by using Aixacct CMA module. Remnant polarization values of Mn-doped 94NBT-6BT MLA for a layer were higher than $6 \mu \mathrm{C} / \mathrm{cm}^{2}$.
\end{abstract}

Keywords Lead-Free, 94NBT-6BT, Manganese Doped, Multilayer, Electrical Properties

\section{Introduction}

Piezoelectric multilayer ceramics have a wide range of applications from aerospace, medical, satellite to defense, automotive and manufacturing industries [1]. The products used are generally PZT based ceramics [2]. Instead of these lead-based products, it is desired to use lead-free products due to RohS standards, and the research goes on about the alternative materials [3]. In this context, actuators produced from the 94NBT-6BT around MPB composition, whose actuator performance is relatively good, have begun to be developed [4].

94NBT-6BT has a potential for multilayer actuators depending on their high strain and high polarization values [5]. Most of the manufacturing method for multilayer ceramic production is tape casting [6]. Although generally solvent-based production route has been chosen due to alkali solubility in water for NBT based compositions in tape casting method, Nd-doped BNKLT tapes have been prepared, 7/3 Ag/Pd electrode paste has been applied on to the surface and successfully multilayer sample produced [7]. Ag/Pd paste was not preferred for reaction potential with Bismuth to occur $\mathrm{BiPd}_{3}$ phase [8].

94NBT-6BT based compositions are researching with modifying compositions such as KNN [9], BKT [10, 11] and oxides like manganese oxide [12], $\mathrm{CuO}$ [13], $\mathrm{Nb}_{2} \mathrm{O}_{5}$ [14], $\mathrm{La}_{2} \mathrm{O}_{3}, \mathrm{CO}_{2} \mathrm{O}_{3}[15,16] \mathrm{Li}_{2} \mathrm{CO}_{3}$ [17], $\mathrm{Ta}_{2} \mathrm{O}_{5}$ [18] that affects piezoelectric properties depending on their valance. Manganese oxide is multivalence additive so, its effects have been changed to its valance and temperature. Manganese can be added to NBT-based system as $\mathrm{MnO}_{2}$ and $\mathrm{MnCO}_{3}$ form [19]. It increases the density, $d_{33}, \mathrm{kp}, \mathrm{Qm}$ values of 94NBT-6BT composition at $1140-1160^{\circ} \mathrm{C}$ [12].

Manganese addition causes oxygen vacancies in the lattice and provides grain growth by the phenomena of mass diffusion in polycrystal materials [20]. In addition, manganese atoms replace $\mathrm{B}$-site atoms in the $\mathrm{ABO}_{3}$ perovskite structure so behaves like acceptor doping $[19,21]$. 
There were some studies about doping manganese to 94NBT-6BT system [22, 23] to achieve an extended working range by investigating the $\mathrm{BaTiO}_{3}$ ratio from 0 to 0.9 and to keep the manganese ratio constant.

For single crystals, manganese doping provides grain growth and decrease in especially leakage current density in 94NBT-6BT composition. For this reason, studies are going in this manner [24]. Although manganese addition to 94NBT-6BT multilayer sample has been studied by Guo et al and showed that Mn-doped-94NBT-6BT multilayer materials can be used as low voltage power supply, effect of manganese has not been mentioned [25].

In this work, manganese amount has been optimized in bulk form of 94NBT-6BT composition, small and large electrical field analysis has been carried out. After decision of manganese ratio in 94NBT-6BT composition, waterbased slurry has been prepared, tape casting has been performed and multilayer ceramics produced by using $7 / 3$ $\mathrm{Ag} / \mathrm{Pd}$ internal electrode to compare with undoped 94NBT 6BT multilayer ceramics.

\section{Experimental}

In this study, $\mathrm{Na}_{2} \mathrm{CO}_{3}$ (Carlo Erba 99,5\%), $\mathrm{Bi}_{2} \mathrm{O}_{3}$ (ABCR 99\%), $\mathrm{BaCO}_{3}$ (Carlo Erba 99\%), $\mathrm{TiO}_{2}$ (Fopol Chemicals 99.9\%) and $\mathrm{MnO}_{2}$ (Merck 90\%) were used to obtain 94NBT-6BT $+\mathrm{x} \quad$ wt $\% \mathrm{MnO}_{2}(\mathrm{x}=0.2, \quad \mathrm{x}=0.3, \quad \mathrm{x}=0.5, \quad \mathrm{x}=0.7$, $\mathrm{x}=1.0$ ) powders by using conventional solid-s tate synthesis method. Abbreviations of the compositions were given in Table $1 . \mathrm{BaCO}_{3}$ has been milled in pulverisette milling to get equiaxed particles. Reagent grade oxides and carbonates were weighted according to stochiometry and milled for 24 hours. After milling, slurry was dried with rotary evaporator. The powder was calcined at $925^{\circ} \mathrm{C}$ for 2 hours to obtain perovskite structure. Then milled for 24 hours with dispersant Darvan-C. The milled slurry was dried at $60^{\circ} \mathrm{C}$ in an oven for 12 hours. For producing pellet samples, these powders were granulated with binder PVA and pressed as pellets. Pellets were cold isostatically pressed under $180 \mathrm{MPa}$ to achieve density and sintered at different sintering temperatures from $1075^{\circ} \mathrm{C}$ to $1175^{\circ} \mathrm{C}$ for 2 hours. Sintered pellets were ground and polished to $1 \mathrm{~mm}$ for small signal measurements and 0,6 $\mathrm{mm}$ for large-signal meas urements. The crystal structure was analyzed using an X-ray diffractometer (XRD, RAD III, Rigaku, Japan). The surface morphology was observed with a field-emission scanning electron microscope (FE-SEM,Jeol, JSM-65OFF, Japan). $d_{33}$ measurements were done by using Sinocera YE2730A $d_{33}$ meter, small-signal measurements were done by using Agilent 4294A gain-phase analyzer.

Table 1. Abbreviation of the 94NBT-6BT ceramics with amount of $\mathrm{MnO}_{2}$ doped

\begin{tabular}{|c|c|}
\hline Abbreviation & Amount of $\mathrm{MnO}_{2}$ doped wt \% \\
\hline 94NBT-6BT & 0 \\
\hline B & 0.2 \\
\hline C & 0.3 \\
\hline E & 0.5 \\
\hline G & 0.7 \\
\hline J & 1.0 \\
\hline
\end{tabular}

For multilayer production, mixed oxides were calcined and milled above.94NBT-6BT and \% wt 0,3 manganese doped 94NBT-6BT powders were manufactured for multilayer ceramics. Then WB4101 binder, distilled water, plasticizer, defoamer, thickener polymers were used to make tape casting slurry. Mars Haake Rheostress 6000 rheometer was used to measure the viscosity of slurry. Prepared slurries were tape cast in KEKO equipment tape caster CAM-L252 that thickness about 50-60 micrometers. Then sheets were dried and cut into 6-inch samples to screen printed with $7 / 3 \mathrm{Ag} / \mathrm{Pd}$ Gwent inner electrode thickness about 3-4 microns and $49 \mathrm{~mm}^{2}$ active areas. Electroded sheets were stacked to have interdigital electrode with the stacker pressure 50 Bar and temperature about $60^{\circ} \mathrm{C}$. After stacking, green multilayer ceramics have been warm isostatically pressed to densify composite structure under $15 \mathrm{MPa}$ at $50^{\circ} \mathrm{C}$ for 3 minutes. Then green dense multilayer ceramics have been cut and sintered at furnace from $1110^{\circ} \mathrm{C}$ to $1125^{\circ} \mathrm{C}$ for $2-4-6$ hours to obtain multilayer ceramics. After sintering, surface finishing has been made to get flat and parallel surfaces. Electrical connections have been made with silver electrode termination paste. Aixacct TF Analyzer 2000 has been used to attain large-signal measurements.

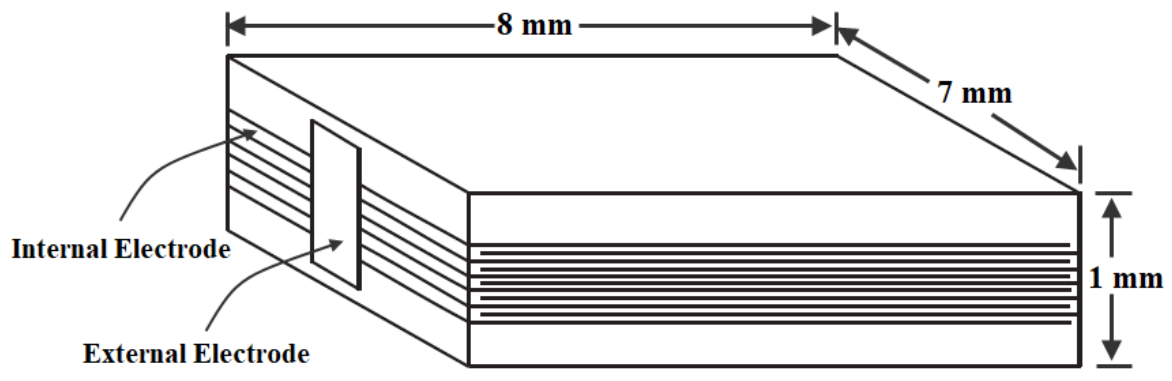

Figure 1. Schematic view of multilayer st ructure 


\section{Results and Discussions}

Figure 2 shows X-ray diffraction patterns of 94NBT$6 \mathrm{BT}+\mathrm{x} \mathrm{w} \% \mathrm{MnO}_{2}$ ceramics for $\mathrm{x}=0,0.2,0.3,0.5,0.7$ and 1.0. It can be seen from the image, no secondary phase has been observed. The peaks shift to the higher angle with increasing amount of Manganese. That shows the tetragonality (c/a) decreases and, perovskite lattice is shortening by obeying Bragg law [20].

Figure 3 shows the density of 94BNT-6BT ceramics as a function of Mn contents. The density value of sintered samples was increased while increasing manganese addition and sintering temperature. When sintering temperature increases above $1125^{\circ} \mathrm{C}$, density of the samples was decreased depending on the loss of $\mathrm{Bi}_{2} \mathrm{O}_{3}$ [12].

Manganese addition increases grain growth due to mass diffusion. Oxygen deficiency causes mass diffusion easier [26]. Figure 4 shows the microstructures of the samples that sintered at $1125^{\circ} \mathrm{C}$ for 2 hours as a function of manganese contents.

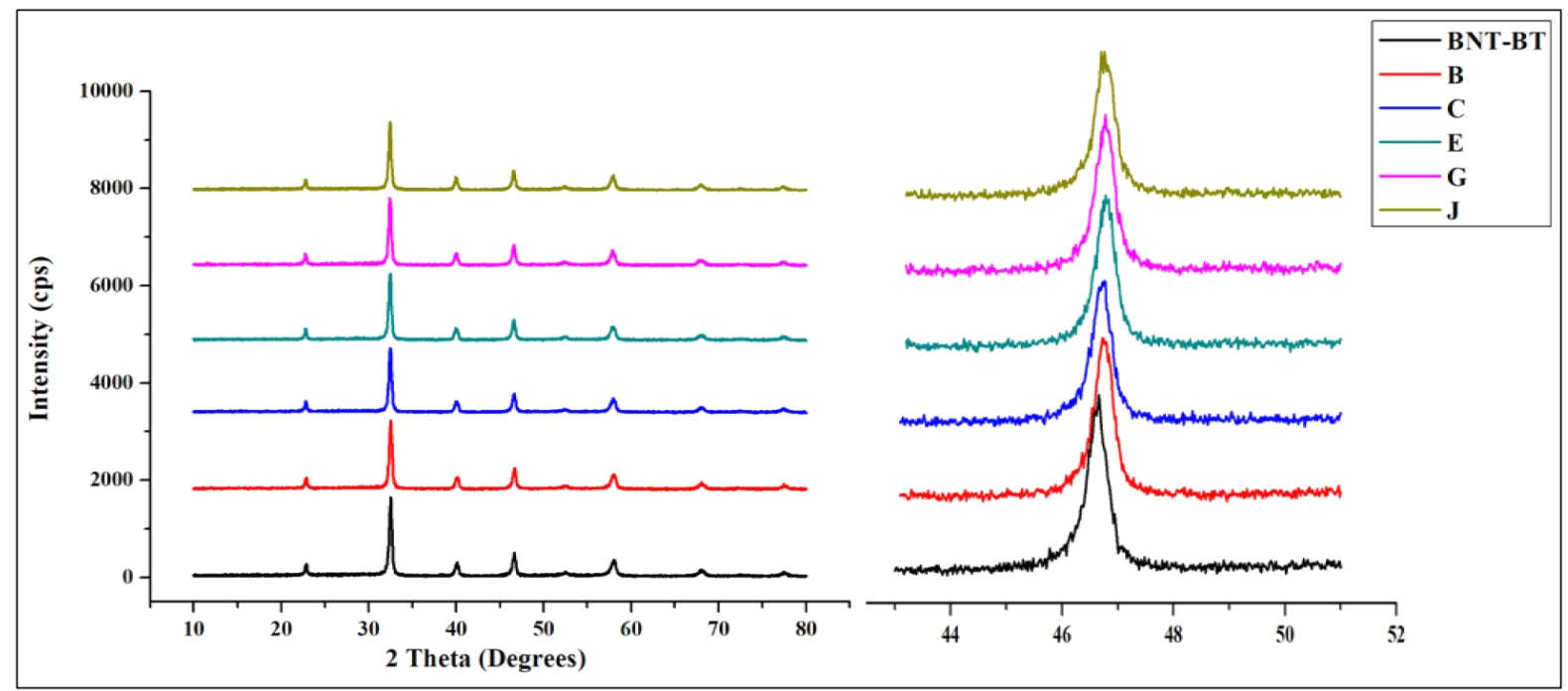

Figure 2. XRD patterns for 94NBT-6BT+x wt $\%$ Mn pellets doped with different amounts of Mn.

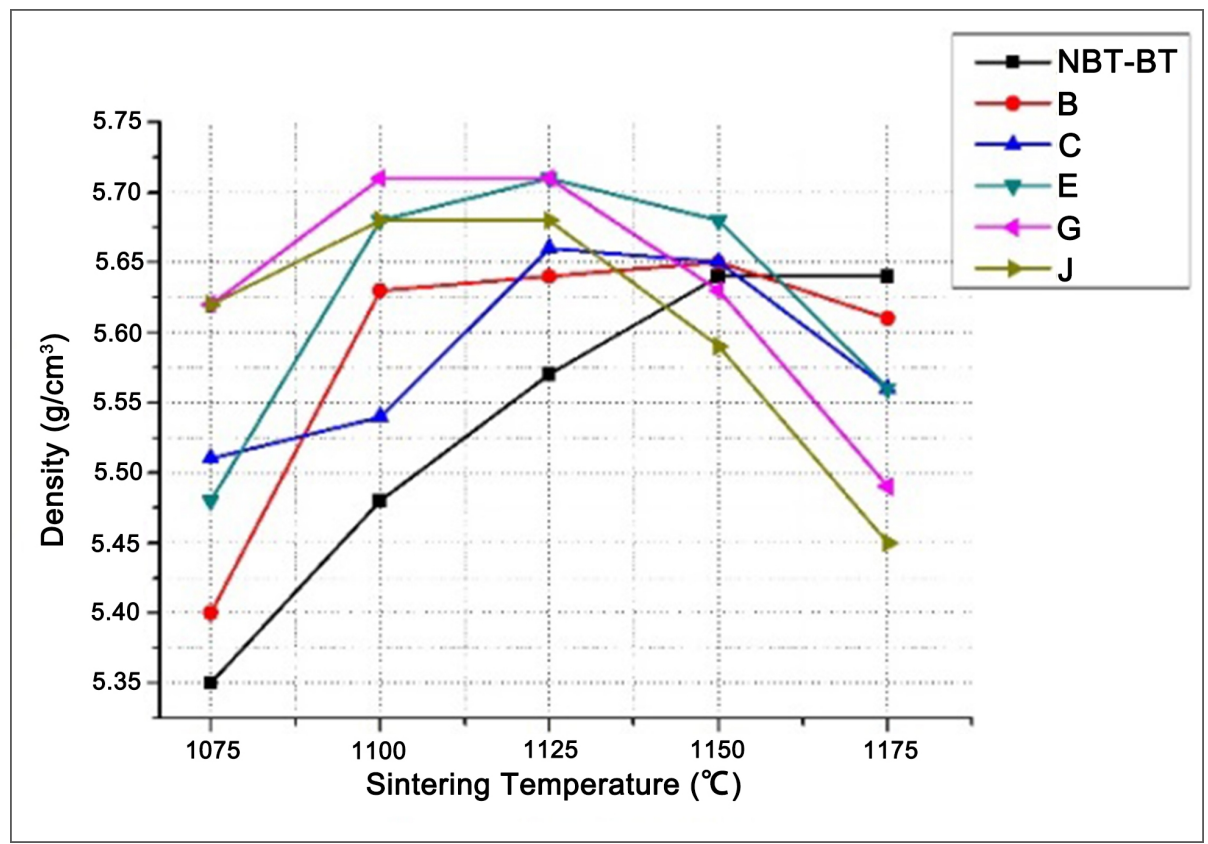

Figure 3. Density values of 94NBT-6BT samples as a function of sintering temperature and amount of Mn dopant 


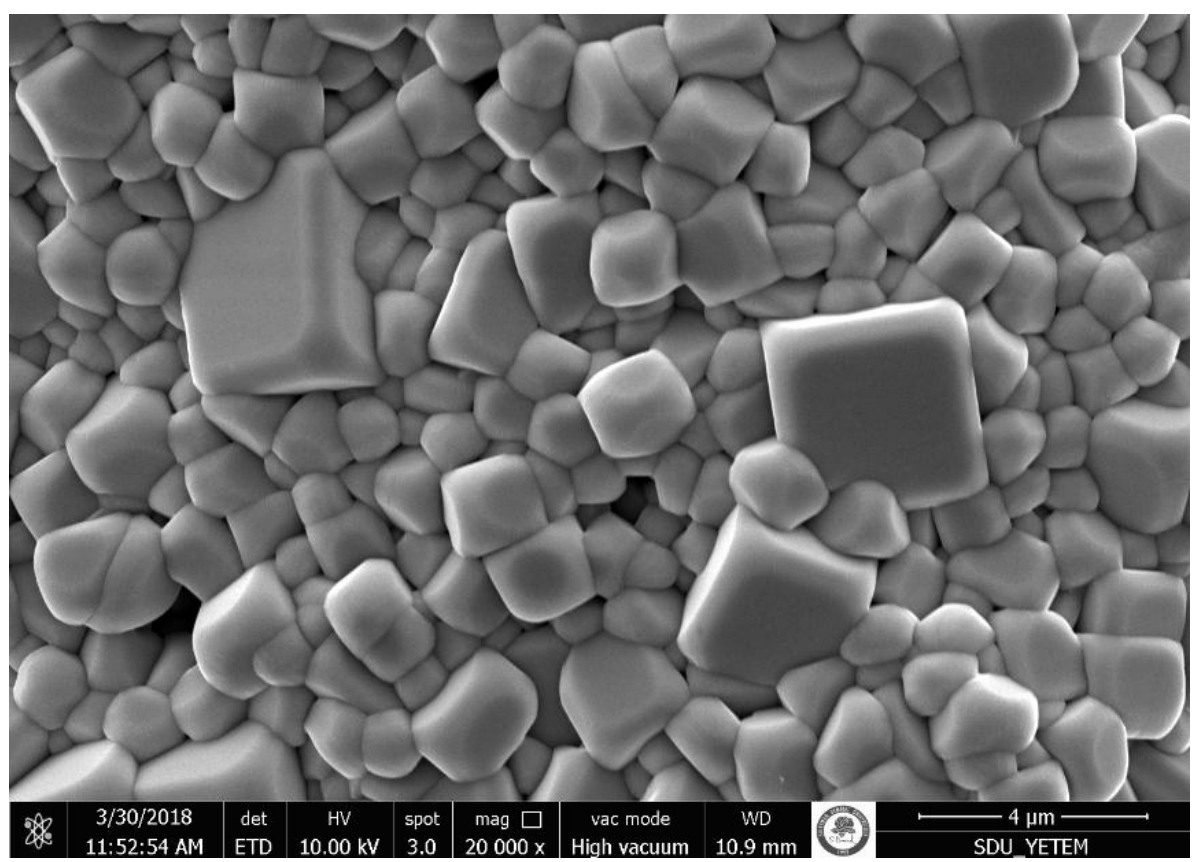

a. Undoped 94NBT-6BT ceramics

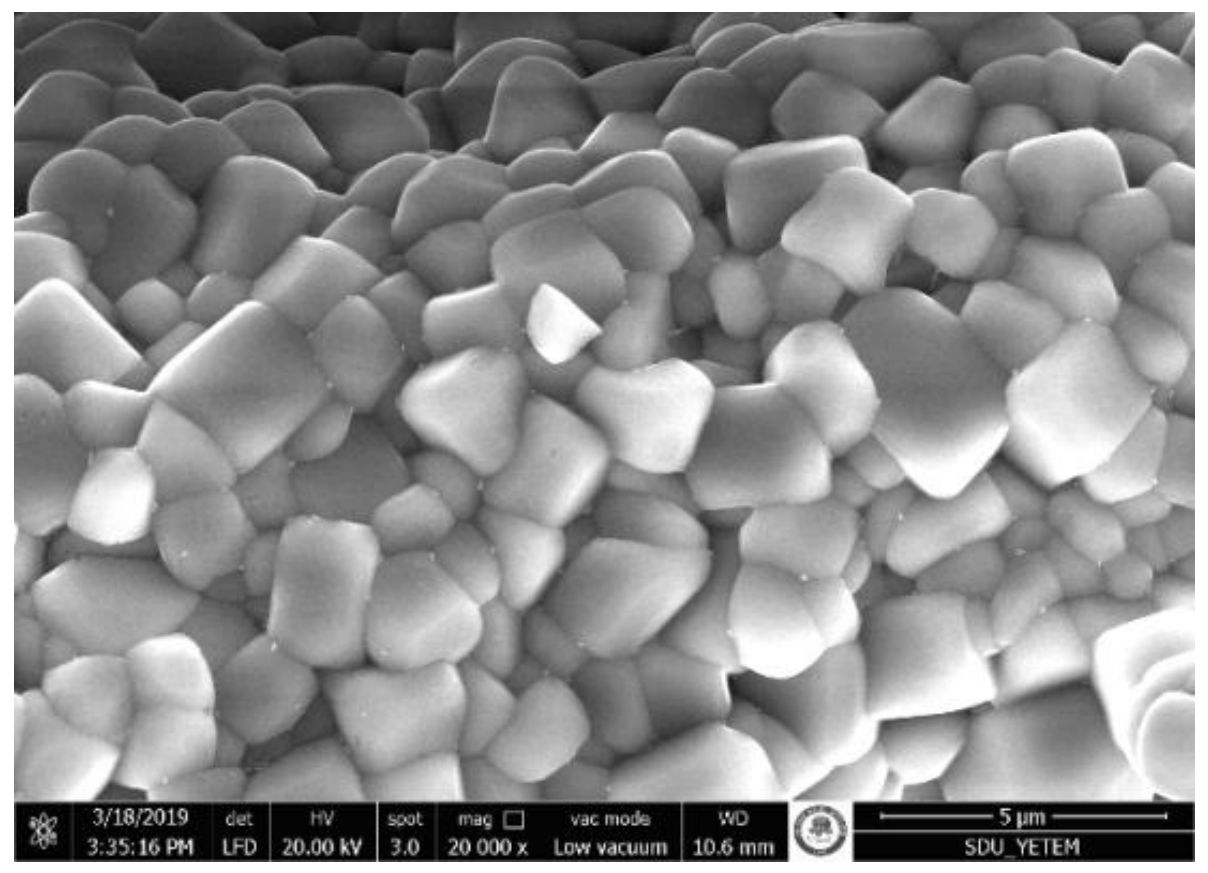

b. 0.2 wt $\%$ Mn-doped 94 NBT-6BT 


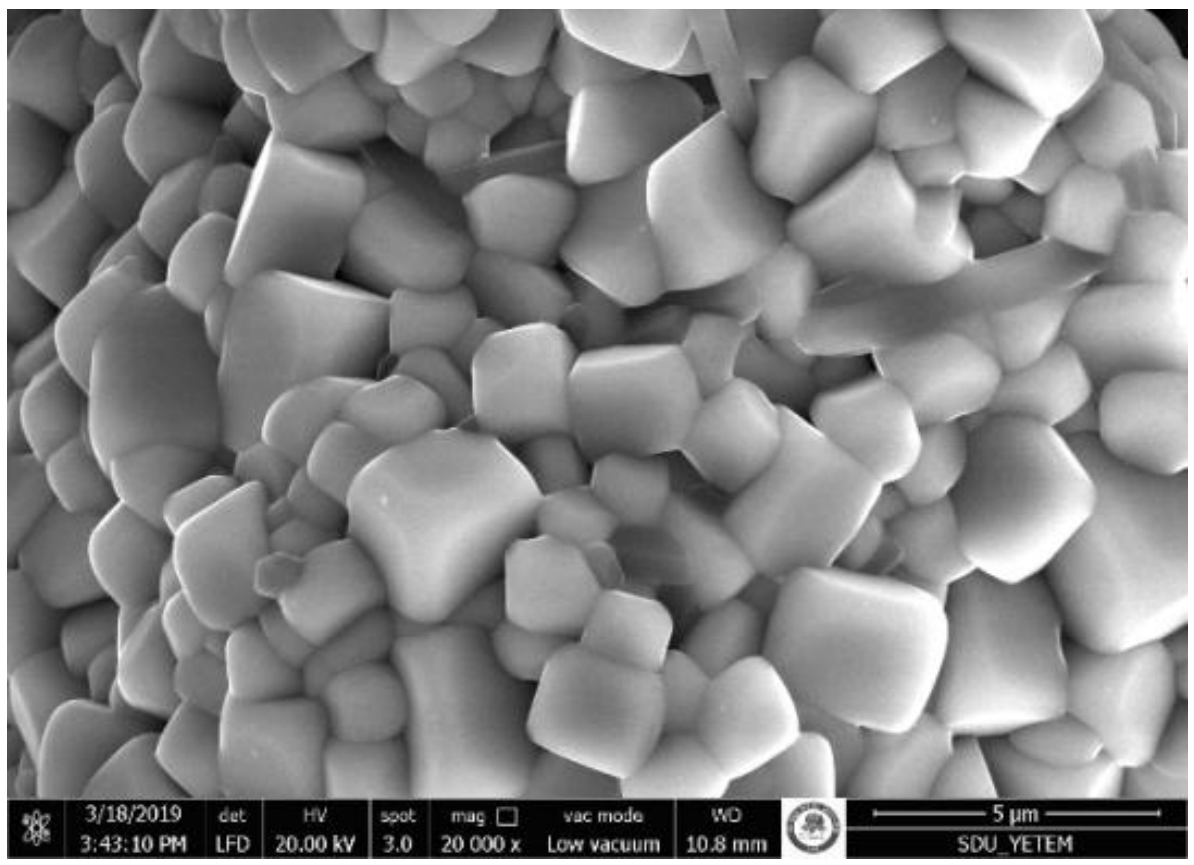

c. 0.3 wt $\%$ Mn-doped 94 NBT-6BT

Figure 4. SEM images of a) 94NBT-6BT b) 0,2\%wt Mn-doped 94NBT-6BT c) 0,3\%wt Mn-doped 94NBT-6BT samples sintered @ $1125 \mathrm{C}-2 \mathrm{~s}$

SEM images show the effect of manganese addition on grain growth of 94NBT-6BT ceramics. As manganese ratio increases, the size of grains increased. Also grains have rounded shape while manganese doped. Manganese behaves like sintering agent.

$d_{33}$ and $k_{p}$ values of the samples were shown in figure 5. $d_{33}$ increases up to $100 \mathrm{pC} / \mathrm{N}$ and $k_{p}$ increases to 0,25 when $0,3 \mathrm{wt} \%$ manganese added to the system. These values are optimum values for the manganese addition on the $94 \mathrm{NBT}-$ 6BT MPB system for the limits of solubility in the lattice. When manganese ratio increases above the solubility limits, manganese atoms pinch the domains by accumulating to the grain boundaries and deteriorate the piezoelectric properties in PZT [27] and 94NBT-6BT [12].

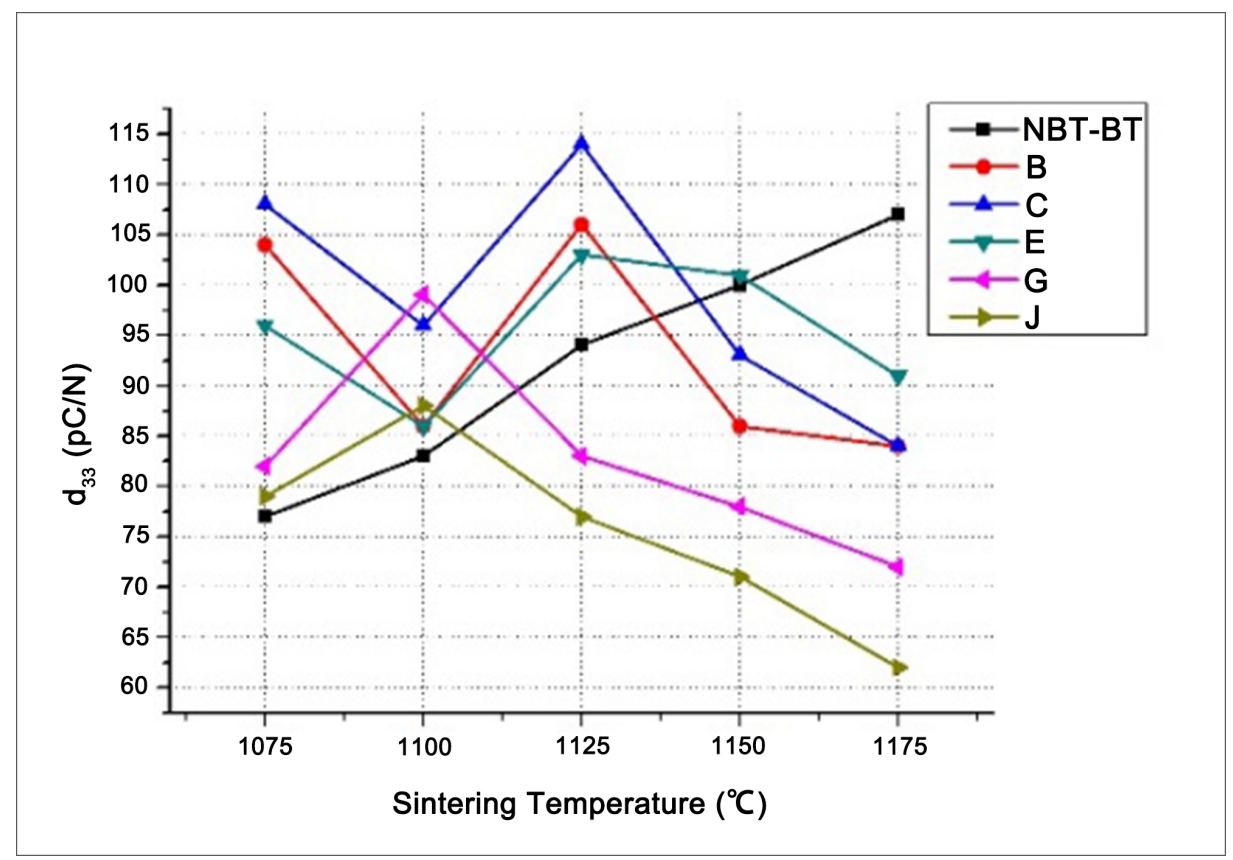




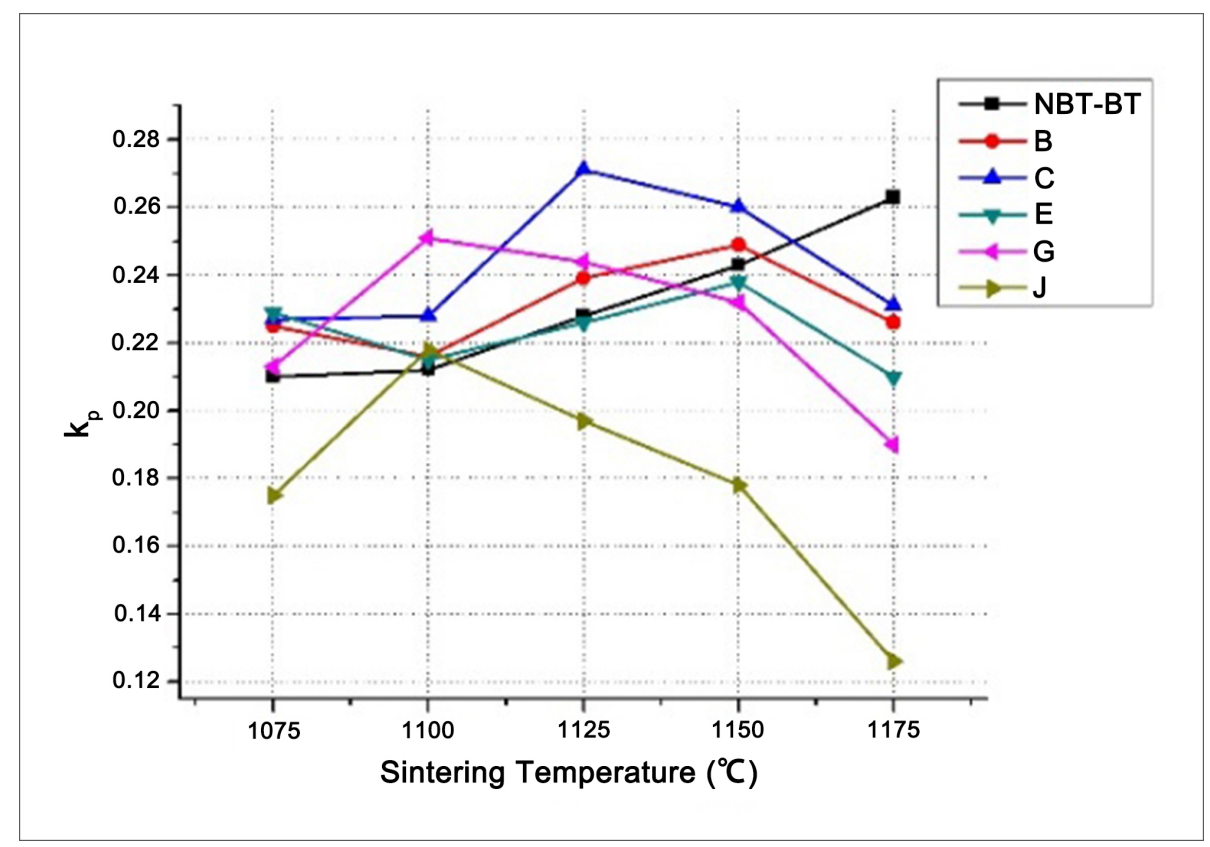

Figure 5. $d_{33}$ and $k_{p}$ results (a-b) of $94 \mathrm{NBT}-6 \mathrm{BT}$ ceramics as a function of temperature and amount of Mn dopant

As shown in figure 6, the mechanical quality factor of manganese doped 94NBT-6BT samples was increased. The following equation mechanical quality factor is the figure of merit defined as internal friction of domain walls underhigh power conditions [28].

$$
Q_{m}=\frac{f_{a}^{2}}{2 \pi C f_{r}\left(f_{a}^{2}-f_{r}^{2}\right) Z_{m}}
$$

$f_{a}$ is antiresonance frequency $(\mathrm{Hz}), \mathrm{f}_{\mathrm{r}}$ is resonance frequency $(\mathrm{Hz}), \mathrm{C}$ is the capacitance $(\mathrm{F}), \mathrm{Z}_{\mathrm{m}}$ is the minimum impedance $(\mathrm{ohm})$ at the resonance frequency. Increasing the mechanical quality factor indicates that manganese atoms are located at B site in the lattice due to oxygen deficiency. Domain walls and motion effects also remanent polarization

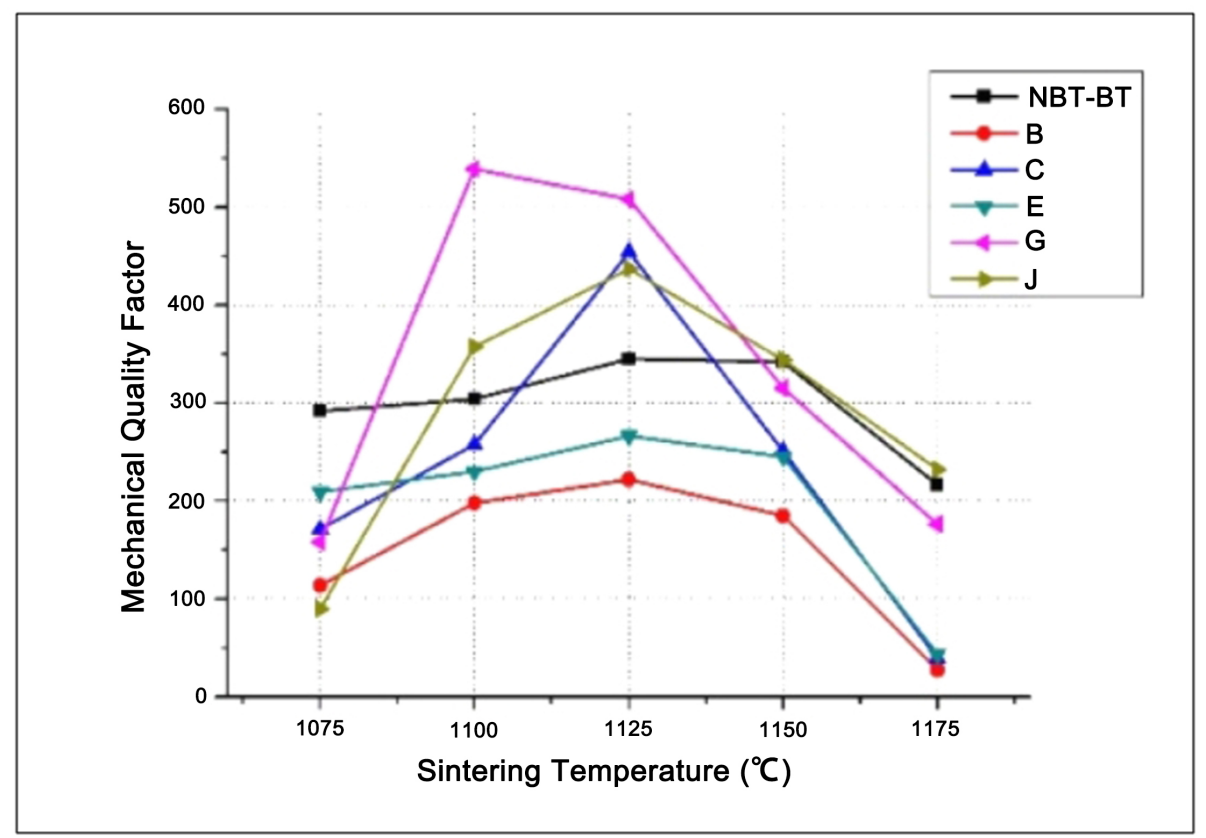

Figu re 6. Mechanical quality factor values of different amount Mn-doped 94NBT-6BT samples depending on sintering temperature 


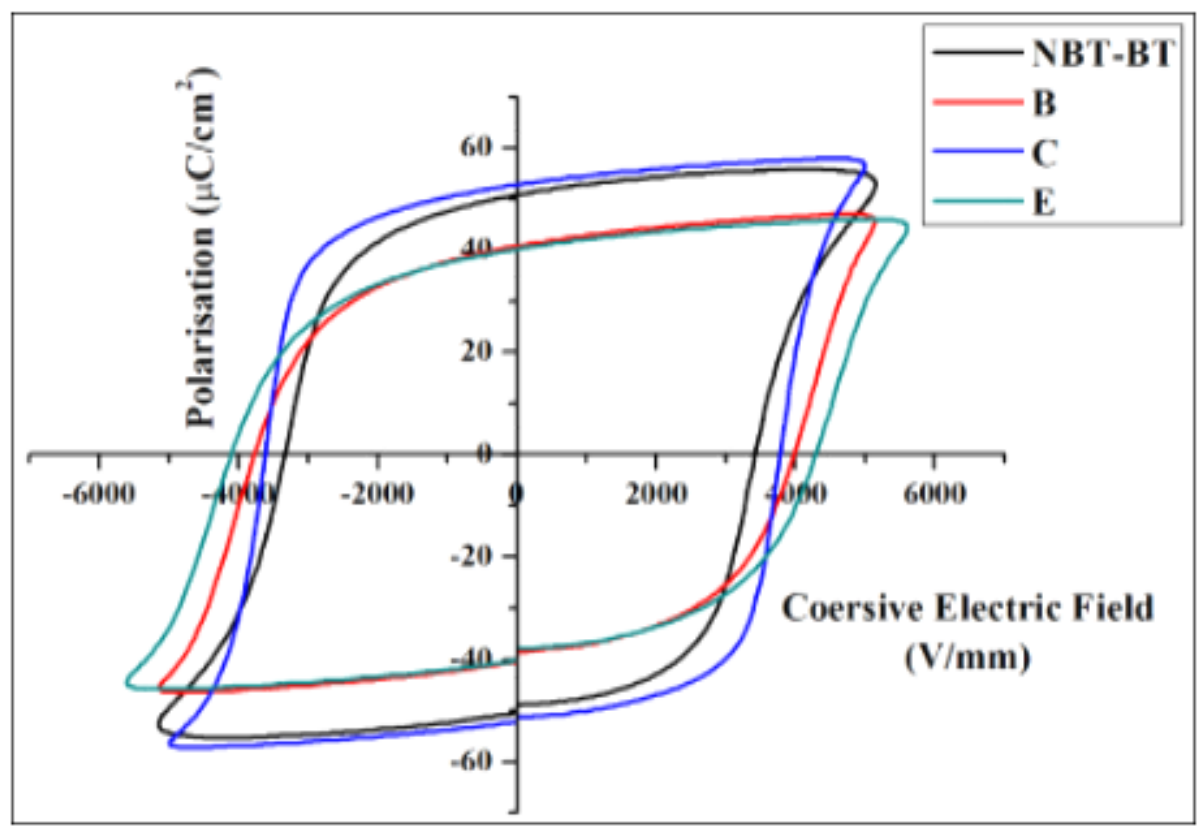

Figure 7. Hysteresis loops for Mn-doped and undoped 94NBT-6BT samples

All the electrical values support the literature to confirm the effect of manganese to 94NBT-6BT [12, 19]. Ceramic s exhibit saturated hysteresis loops (figure 7). Manganese doped 94NBT-6BT composition exhibit larger polarization. If manganese ratio increases up to optimum value of 0,3 wt $\%$, not only hysteresis can exhibit saturated value but also samples go into breakdown. Therefore, measurable hysteresis results obtained only from B, C and E compositions.

Doping manganese has increased the conductivity of samples when the amount is increasing to the solubility limits, leakage current increases [29]. For this reason, 0,3 $\mathrm{wt} \% \mathrm{Mn}$-doped ceramics have been selected to produce ML ceramics.

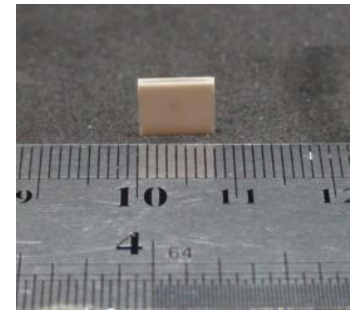

a

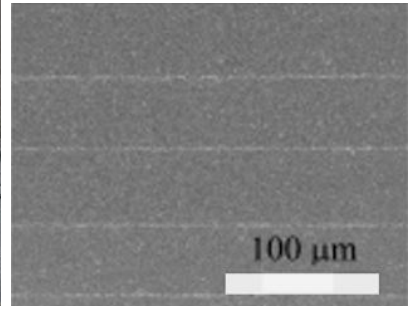

b
Figure 8. a) Photograph of a multilayer ceramic actuator b) crosssectional SEM

The behavior of NBT materials was not fully resolved in water-based tape casting slurry due to possible alkali solubility in water, but process can be applied [7]. The $8 \times 7 \times 1 \quad \mathrm{~mm}^{3}$ size $0,3 \mathrm{wt} \%$ Manganese doped and undoped 94NBT-6BT MLAs were fabricated by water-based tape casting technique that is shown in figure 8 .

These MLAs were sintered at different sintering temperatures and time. Internal electrode behavior changes depending on sintering conditions. Thermal mismatch of electrode and ceramic causes deformation on inner electrode and delamination defect while sintering [30] and decrease in polarisation loop [31]. Also Ag-Pd electrode was not preferred before it was known that the presence of excess bismuth exists in the composition and would cause the reaction with palladium [32].

It can be clearly seen that homogenous floating of electrode of Mn-doped 94NBT-6BT multilayer samples from figure 9 (d-f) that sintered at $1115^{\circ} \mathrm{C}-2$ hours. Optimum sintering conditions for multilayer materials can be found to obtain max values of polarization to electrical field applied [33]. Figure 10 a-b presents room temperature polarization-electric field (P-E) hysteresis loops of the 94NBT-6BT multilayer ceramics sintered at $1115^{\circ} \mathrm{C}$ and $1120^{\circ} \mathrm{C}$ for different hours. Remnant polarization (Pr) values of samples were about $5 \mu \mathrm{C} / \mathrm{cm}^{2}$. Increasing sintering time causes decrease in coercive electric field. Figure 10c shows Mn-doped 94NBT-6BT multilayer samples sintered at $1115^{\circ} \mathrm{C}$ for 2-4-6 hours. Remnant polarization value for 2 hours sintered samples were above $6 \mu \mathrm{C} / \mathrm{cm}^{2}$. Increasing sintering time causes increase in coercive electrical field in NBT-H-ML samples. 

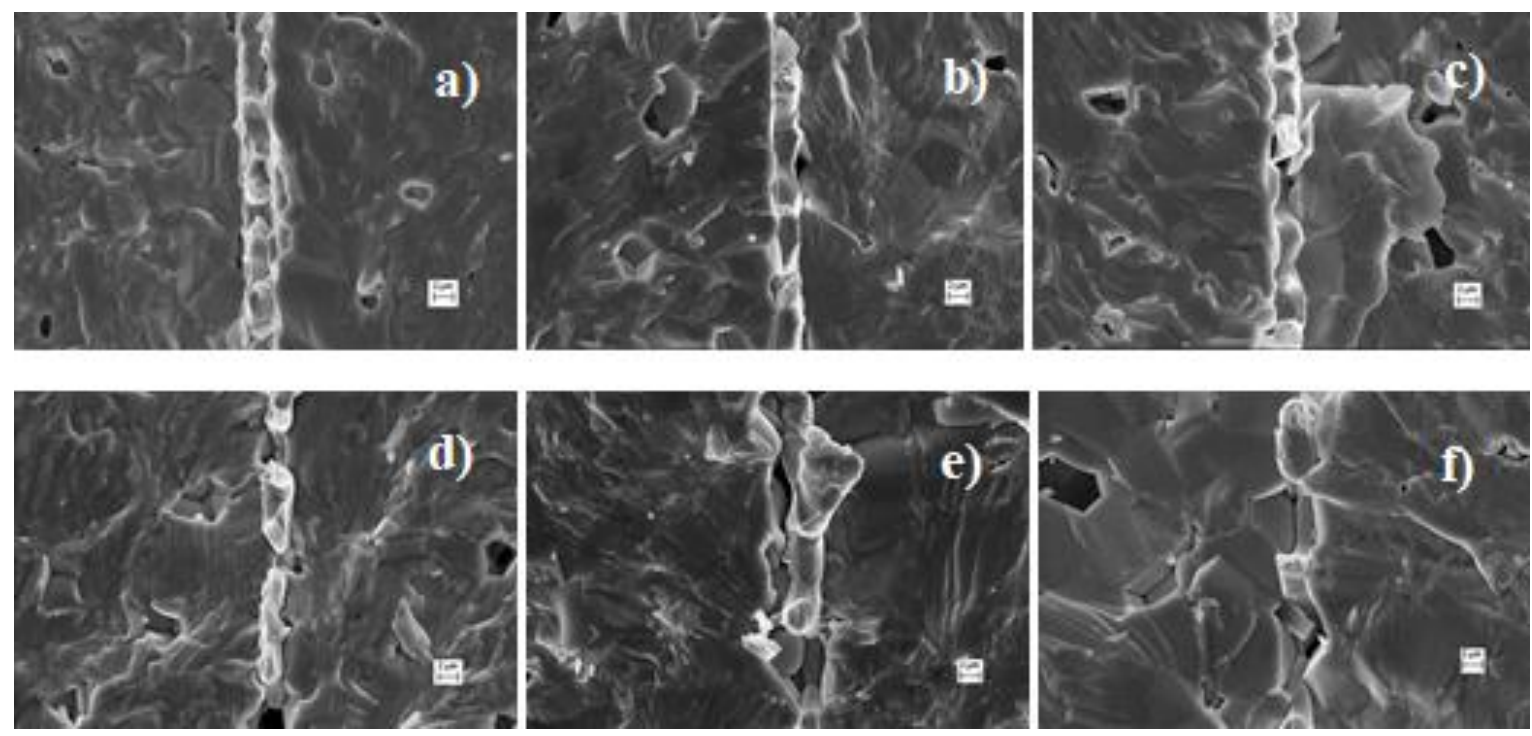

Figure 9. SEM analysis for 94NBT-6BT multilayer ceramics sintered @ $1115^{\circ} \mathrm{Ca}$ a-c) 94NBT-6BT samples 2-4-6 hours d-f)Mn-doped 94NBT-6BT samples 2-4-6hours
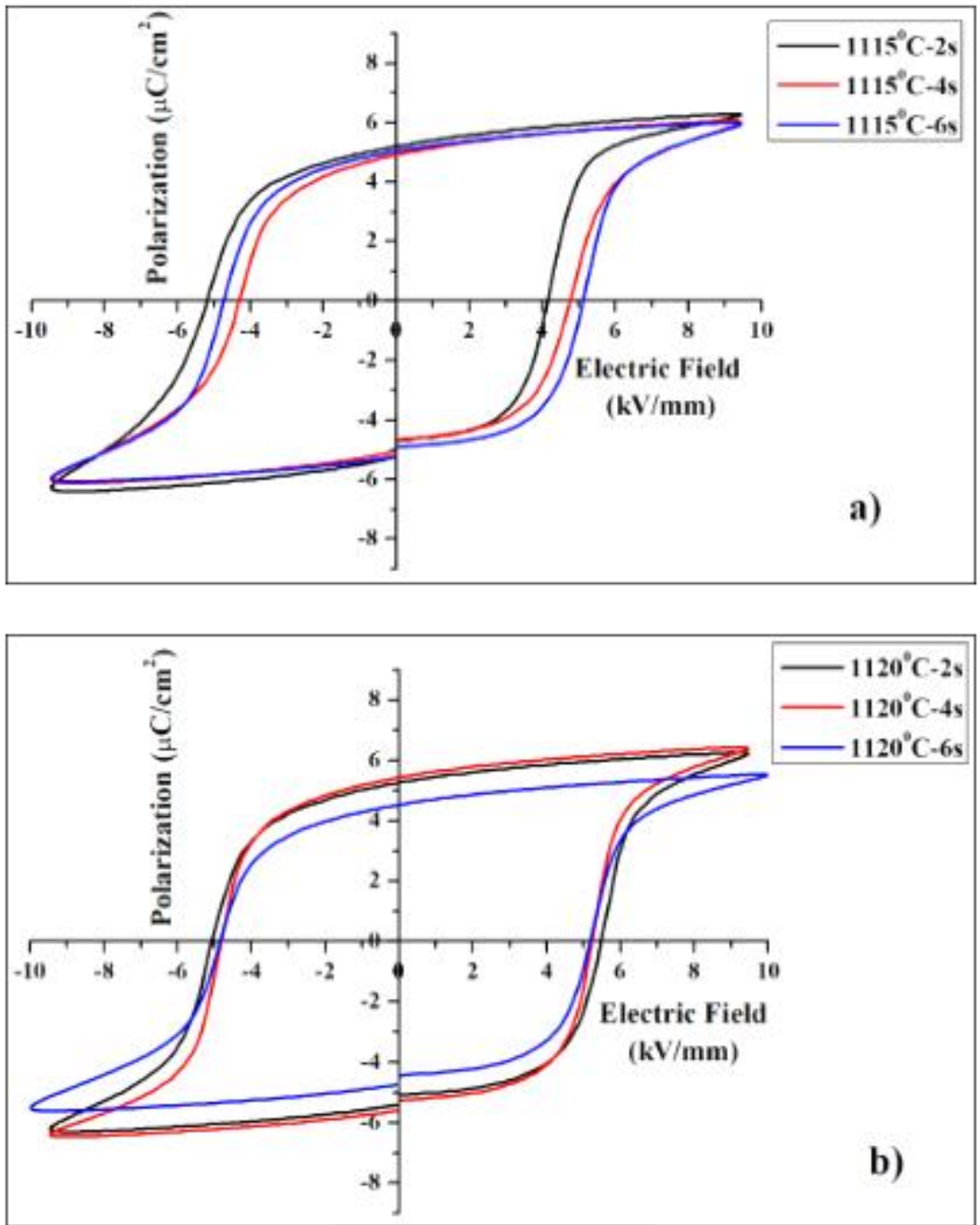


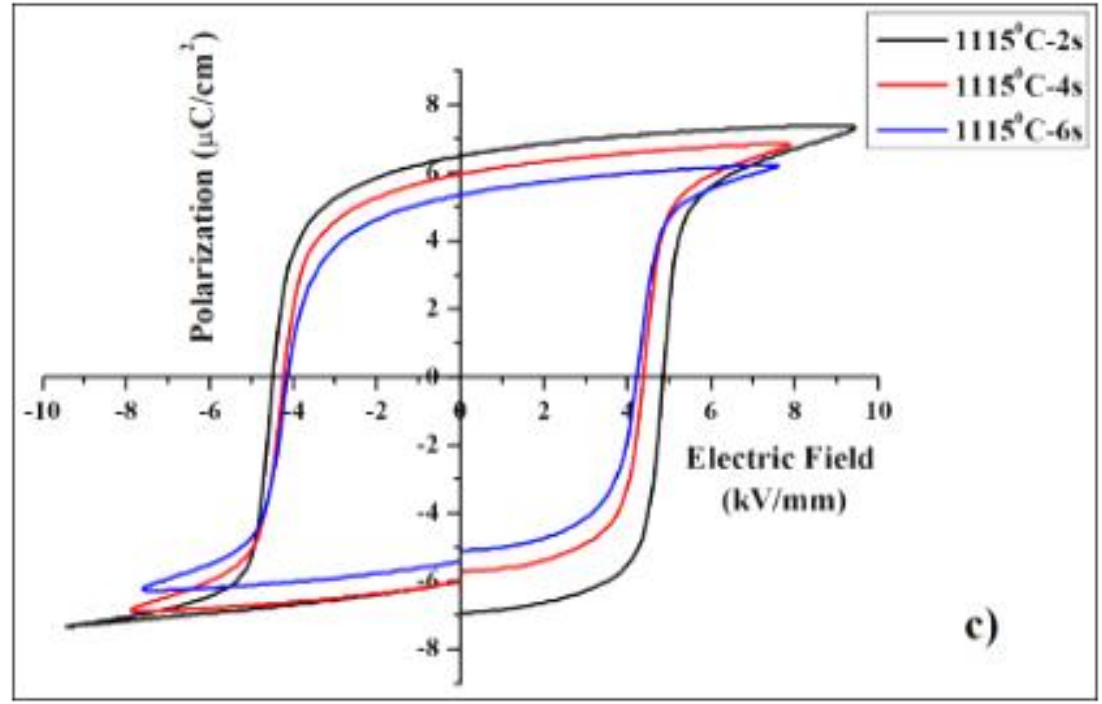

Figure 10. Hysteresis loops of 94NBT-6BT multilayer samples sintered at different temperatures and time a) $1115^{\circ} \mathrm{Cb}$ ) $\left.1120^{\circ} \mathrm{Cc}\right) \mathrm{Mn}-\mathrm{doped} 1115^{\circ} \mathrm{C}$

\section{Conclusions}

Manganese doped 94NBT-6BT ceramics synthesized by solid-state method was investigated. According to obtained small and large signal results of bulk samples, amount of manganese has been optimized about $0.3 \mathrm{wt} \%$. Remnant polarization value has been increased to $40 \mu \mathrm{C} / \mathrm{cm}^{2}$ by optimizing manganese ratio. Based on the obtained results, multilayer samples of 94NBT-6BT and doped 94NBT-6BT compositions have been produced successfully and measurements have been done. Sintering temperature and time for sintering the ceramic and metal-ceramic interaction has been optimized for 94NBT-6BT and Mndoped 94NBT-6BT multilayer structures. As expected, Mn-doped 94NBT-6BT multilayer ceramics have higher remnant polarization values than 94NBT-6BT multilayer ceramics apart from size effect. In future works, electrical switching performance of 94NBT-6BT and Mn-doped 94NBT-6BT multilayer ceramics will be held and compared.

\section{Acknowledgements}

This work was supported by Science Research Projects of Anadolu University (Projects No: $1705 \mathrm{~F} 199$ and 1605F333) and Foundation of $\mathrm{PhD}$ Thesis Support Program in Afyon Kocatepe University in Turkey (Project No:17.FEN.BİL.71). The authors gratefully thank to Nebahat Biyklı for experimental supports, and following people for their supports Ali Biykll, Görkem Hatipoğlu, Hakan Güleç, İrem Panta, Yiğitalp Okumuş and Enes Düden. Thanks are also to Serhat Tikı, Hakan Şahin (Afyon Kocatepe University TUAM) and Salih Akyürekli (Suleyman Demirel University) for their help in the SEM and XRD measurements. Special thanks to Assist. Prof. Dr. Metin Özgül for his valuable comments.

\section{REFERENCES}

[1] Uchino K., Takahashi S. "Multilayer Ceramic Actuators, Current Opinion" Ceramics, Composites and Intergrowths, 698- 705, 1996.

[2] Jo W., Daniels J.E., Jones J.L., Tan X., Thomas P.A., Damjanovic D., Rödel J. "Evolving morphotropic phase boundary in lead-free $\left(\mathrm{Bi}_{1 / 2} \mathrm{Na}_{1 / 2}\right) \mathrm{TiO}_{3}-\mathrm{BaTiO}_{3}$ piezoceramics" Journal of Applied Phy sics, Vol. 109, No.1, 014110-014117, 2011.

[3] Takenaka T., Nagata H. "Current status and prospects of lead-free piezoelectric ceramics" Journal of the European Ceramic Society, Vol.25, 2693-2700, 2005.

[4] Chen P.Y., Chen C.S. , Tu C.S. , Cheng C.D., Cherng J.S. "Relaxor effect on electric field induced large strain in $(1-\mathrm{x})\left(\mathrm{Bi}_{0.5} \mathrm{Na}_{0.5}\right) \quad \mathrm{TiO}_{3}-\mathrm{xBaTiO}_{3}$ lead-free piezoceramics" Ceramics International, Vol.40, 6137-6142, 2014.

[5] Rödel J., Webber K.G., Dittmer R., Jo W., Kimura M., Damjanovic D. "Transferring lead-free piezoelectric ceramics into application" Journal of the European Ceramic Society, Vol.35, 1659-1681, 2015.

[6] D Galassi C., Roncari E., Capiani C., Pinasco P. "PZT-based Suspensions for Tape Casting" Journal of the European Ceramic Society, Vol.17, 367-371, 1997.

[7] Krauss W., Schütz D., Naderer M., Orosel D., Reichmann K. "BNT-based multilayer device with large and temperature independent strain made by a water-based preparation process" Journal of the European Ceramic Society, Vol.31, 1857-1860, 2010.

[8] Wang S.F., Huebner W. "Interaction of Ag/Pd metallization with lead and bismuth oxide-based fluxes in multilayer ceramics capacitors" Journal of American Ceramic Society, Vol.75, No.9, 2339-2352, 1992.

[9] Jo W., Granzow T., Aulbach E., Rödel R., Damjanovic D. 
"Origin of the large strain response in $\mathrm{K} 0.5 \mathrm{Na0} .5 \mathrm{NBO} 3$ modified $\left(\mathrm{Bi}_{0.5} \mathrm{Na}_{0.5}\right) \mathrm{TiO}_{3}-\mathrm{BaTiO}_{3}$ lead-free piezoceramics" Journal of Applied Phy sics, Vol.105, 094102, 2009.

[10] Shieh J., Lin Y.C., Chen C.S. "Intricate straining of manganese-doped $\quad\left(\mathrm{Bi}_{0.5} \mathrm{Na}_{0.5}\right) \mathrm{TiO}_{3}-\mathrm{BaTiO}_{3}-\left(\mathrm{Bi}_{0.5} \mathrm{~K}_{0.5}\right)$ $\mathrm{TiO}_{3}$ lead-free ferroelectric ceramics" Journal of Physcs D: Applied Phy sics Vol.43, 025404 (7pp), 2010.

[11] Li Y., Chen W., Xu Q., Zhou J., Gu X., Fang S. "Electromechanical and dielectric properties of $\mathrm{Na}_{0.5} \mathrm{Bi}_{0.5} \mathrm{TiO}_{3}-\mathrm{K}_{0.5} \mathrm{Bi}_{0.5} \mathrm{TiO}_{3}-\mathrm{BaTiO}_{3}$ lead-free ceramics" Materials Chemistry and Physics, Vol.94, 328-332, 2005.

[12] Li X.J., Wang Q., Li Q.L. "Effects of $\mathrm{MnO} 2$ addition on microstructure and electrical properties of $\left(\mathrm{Bi}_{0.5} \mathrm{Na}_{0.5}\right)$ ${ }_{0.94} \mathrm{Ba}_{0.06} \mathrm{TiO}_{3}$ ceramics" Journal of Electroceramics, Vol.20, 89-94, 2008.

[13] Zidi N., Chaouchi A., d'Astorg S., Rguiti M., Courtois C. "Dielectric and impedance spectroscopy characterizations of $\mathrm{CuO}$ added $\left(\mathrm{Na}_{0.5} \mathrm{Bi}_{0.5}\right)_{0.94} \mathrm{Ba}_{0.06} \quad \mathrm{TiO}_{3}$ lead-free piezoelectric ceramics" Journal of Alloys and Compounds, Vol.590, 557-564, 2014.

[14] Li H., Kang J., Guo F., Qu Y., Yang D. "Effect of the $\mathrm{Nb}_{2} \mathrm{O}_{5}$ content on electrical properties of lead-free $\mathrm{BaTiO}_{3}$ $\mathrm{Bi}_{0.5 \mathrm{Na}} \mathrm{Na}_{5} \mathrm{TiO}_{3}$ ceramics" Ceramics International Vol.39, 7589-7593, 2013.

[15] Li H.D., Feng C.H., Yao W.L. "Some effects of different additives on dielectric and piezoelectric properties of $\left(\mathrm{Bi}_{1 / 2} \mathrm{Na}_{1 / 2}\right) \mathrm{TiO}_{3}-\mathrm{BaTiO}_{3}$ morphotropic-phase-boundary composition” Materials Letters, Vol.58, 1194 - 1198, 2004.

[16] Panda P.K. "Review: environmental friendly lead-free piezoelectric materials" Journal of Materials Science, Vol.44, 5049-5062, 2009.

[17] Zhang Y., Chu R., Xu Z., Chen Q., Liu Y., Zhang G. "Effects of $\mathrm{Li}_{2} \mathrm{CO}_{3}$ on the sintering behavior and piezoelectric properties of $\mathrm{Bi}_{2} \mathrm{O}_{3}$-excess $\left(\mathrm{Bi}_{0.5} \mathrm{Na}_{0.5}\right)_{0.94} \mathrm{Ba}_{0.06} \mathrm{TiO}_{3}$ ceramics" Current Applied Phy sics, Vol.12, 204-209, 2012.

[18] Zuo R., Ye C., Fang X., Li J. "Tantalum doped $0.94 \mathrm{Bi}_{0.5} \mathrm{Na}_{0.5} \mathrm{TiO}_{3}-0.06 \mathrm{BaTiO}_{3}$ piezoelectric ceramics" Journal of the European Ceramic Society, Vol.28, 871-877, 2008.

[19] Fan G.F., Lu W.Z., Wang X.H., Liang F. "Effects of manganese additive on piezoelectric properties of $\left(\mathrm{Bi}_{1 / 2} \mathrm{Na}_{1 / 2}\right) \mathrm{TiO}_{3}-\mathrm{BaTiO}_{3}$ ferroelectric ceramics" Journal of Materials Science, Vol. 42, 472-476, 2007.

[20] X.Y.Zhou, H.S.Gu, Wang Y., W.Y.Li, Zhou T.S. "Piezoelectric properties of Mn-doped $\left(\mathrm{Na}_{0.5} \mathrm{Bi}_{0.5}\right)_{0.92}$ $\mathrm{Ba}_{0.08} \mathrm{TiO}_{3}$ ceramics" Materials Letters, Vol.59, 1649 1652, 2005.

[21] E. Erdem, S. Schaab, W. Jo, A. Ozarowski, J. van Tol, and R.-A. Eichel "High-Frequency EPR Analysis of $\mathrm{MnO}_{2}$ Doped $\left[\mathrm{Bi}_{0.5} \mathrm{Na}_{0.5}\right] \mathrm{TiO}_{3}-\mathrm{BaTiO}_{3}$ Piezoelectric Ceramics Manganese Oxidation States and Materials 'Hardening'" Ferroelectrics, Vol. 428, 116, 2012.

[22] Sapper E., Novak N., Jo W., Granzow T., Rödel J. “Electricfield-temperature phase diagram of the ferroelectric relaxor system (1 -x) $\mathrm{Bi}_{1 / 2} \mathrm{Na}_{1 / 2} \mathrm{TiO}_{3}-\mathrm{xBaTiO}_{3}$ doped with manganese" Journal of Applied Physics, Vol.115, 194104, 2012.
[23] Sapper E., Schaab S.,Jo W.,Granzow T.,Rödel J. “Influence of electric fields on the depolarization temperature of $\mathrm{Mn}$ doped (1-x) $\mathrm{Bi}_{1 / 2} \mathrm{Na}_{1 / 2} \mathrm{TiO}_{3}-\mathrm{xBaTiO}_{3}$ " Journal Of Applied Phy sics, Vol.111, 014105, 2012.

[24] Yao J., Ge W., Yan L., Reynolds W.T., Li J., Viehland D., Kiselev D.A. Kholkin A.L., Zhang Q., Luo H. "The influence of $\mathrm{Mn}$ substitution on the local structure of $\mathrm{Na}_{0.5} \mathrm{Bi}_{0.5} \mathrm{TiO}_{3}$ crystals: Increased ferroelectric ordering and coexisting octahedral tilts" Journal of Applied Physics, Vol.111, 064109, 2012.

[25] Guo M., Jiang X.P., Lam K.H., Wang S., Sun C.L.., Chan H.L.W., Zhao X.Z. "Lead-free multilayer piezoelectric transformer" Review of Scientific Instruments Vol.78, 016105-1-4, 2007.

[26] S.J. Zhang, R. Xia, T. R. Shrout, "Low temperature sintering and properties of piezoelectric ceramics PSNT-Mn with $\mathrm{LiBiO}_{2}$ addition" Materials Science and Engineering B, Vol.129, 131, 2006.

[27] L.S. He, C.E. Li. "Effects of addition of $\mathrm{MnO}$ on piezoelectric properties of lead zirconate titanate" Journal of Materials Science, Vol.35, 2477-2480, 2000.

[28] Shekhani H.N., Uchino K. "Evaluation of the machanical quality factor under high power conditions in piezoelectric ceramics from electrical power" Journal of the European Ceramic Society, Vol.35, 541-544, 2015.

[29] Aksel E., Jakes P., Erdem E., Symth D.M., Ozarowski A., Tol J.V., Lones J.L., Eichel R.A. "Processing of Manganese-Doped $\quad\left[\mathrm{Bi}_{0.5} \mathrm{Na}_{0.5}\right] \mathrm{TiO}_{3} \quad$ Ferroelectrics: Reduction and Oxidation Reactions During Calcination and Sintering" Journal of American Ceramic Society, Vol.94 No.5, 1363-136, 2011.

[30] Choi M.S., Kim S.H., Kim Y.H., Kim W., Jeong S.J., Song J.S., Lee J.S., "Application of Ag-ceramic composite electrodes to low firing piezoelectric multilayer ceramic actuators" Journal of Electroceramics, Vol.20, 225-229, 2008.

[31] Nguyen V.Q., Kang J.K., Han H.S., Lee H.Y., Jeong S.J., Ahn C.W., Kim I.W., Lee J.S. Bi-based lead-free ceramic multilayer actuators using $\mathrm{AgPd}-\left(\mathrm{Na}_{0.51} \mathrm{~K}_{0.47} \mathrm{Li}_{0.02}\right)$ $\left(\mathrm{Nb}_{0.8} \mathrm{Ta}_{0.2}\right) \mathrm{O}_{3}$ composite inner electrodes" Sensors and Actuators A, Vol: 200, 107-1132013.

[32] Newnham R.E. "Structure Property Relations for Ceramic Capacitors. Workshop on the Reliability of Multilayer Ceramic Capacitors, National Academy of Sciences, Washington D.C., 29-31 March 1982, 53-66.

[33] S.A. Hooker "Characterizing reliability of multilayer PZT actuators" Smart Structures and Materials 2006: Active Materials: Behavior and Mechanics, edited by William D. Armstrong, Proc. of SPIE Vol. 6170, 61700F, 2006. 